\title{
Boron, aluminum, nitrogen, and oxygen impurities in silicon carbide
}

\author{
S.I. Vlaskina ${ }^{1}$, V.I. Vlaskin ${ }^{2}$, S.A. Podlasov ${ }^{2}$, V.E. Rodionov ${ }^{2}$, G.S. Svechnikov ${ }^{2}$ \\ ${ }^{1}$ Dong Seoul College, 461-714, 423, \\ Bokjung-Dong, Sungnam-city, Kyonggi-do, Korea \\ Phone: 82 (031) 7202141, fax 82(031) 7202261; e-mail: svitlana@haksan.dsc.ac.kr \\ ${ }^{2} V$. Lashkaryov Institute of Semiconductor Physics, NAS of Ukraine \\ 45, prospect Nauky, 03028 Kyiv, Ukraine \\ Phone: 380(44) 5253792, fax 380 (44) 5258342; e-mail: businkaa@mail.ru
}

\begin{abstract}
Diffusion of boron, aluminum, and oxygen was conducted at temperatures $1600-1700{ }^{\circ} \mathrm{C}$. Very pure original $\mathrm{n}$-SiC crystal (6H-SiC) specially grown by the Lely method annealed in oxygen during $2 \mathrm{~h}$ at $1700{ }^{\circ} \mathrm{C}$, in argon during $2 \mathrm{~h}$ at $1700^{\circ} \mathrm{C}$, with aluminum and silicon oxide powder during $2 \mathrm{~h}$, and with boron oxide and aluminum during $0.5 \mathrm{~h}$. Electrical characterization of the silicon carbide samples was done by the Hall effect measurements using the square van der Pauw method to determine the sheet resistance, mobility, and free carrier concentration. The model of deep donor level as a complex of nitrogen atom replacing carbon with adjacent silicon vacancy is suggested.
\end{abstract}

Keywords: silicon carbide, diffusion, $p-n$ junction.

Manuscript received 09.02.07; accepted for publication 24.04.07; published online 19.10.07.

\section{Introduction}

Silicon carbide devices have important applications in motor drives, in power transmission systems, in information systems, in field effect devices (MOSFET, MESFET, JFET, BJT), in the Shottky barrier diodes (SBDs), in switch elements, and in all cases where silicon-based semiconductor electronics cannot operate [1-3].

Such impurities as boron, oxygen, and aluminum are used in fabrication of all devices for the formation of junctions, contacts, and the Shottky barriers $[4,5]$. Diffusion of such impurities takes place in the process of fabrication of a junction or in the process of postimplantation annealing. The diffusion experiment had been performed with boron in $4 \mathrm{H}-$ and $6 \mathrm{H}-\mathrm{SiC}$ at temperatures between 1700 and $2000{ }^{\circ} \mathrm{C}$.

Boron depth profiles had been measured with secondary ion mass spectroscopy on implantation and recovery annealing [6] and well described on the basis of the kick-out mechanism giving evidence for the significant role of Si self-interstitials in boron diffusion $[7,8]$.

Silicon carbide $6 \mathrm{H}-\mathrm{SiC}$ crystals with a boron impurity on a silicon site [9] and the role of intrinsic point defects are in focus of the theoretical studies and industrial researches $[10,11]$. Even the process of selfdiffusion of silicon in $\mathrm{SiC}$ is not investigated well until now $[12,13]$ and a lot of fundamental questions are under investigation.

Diffusion of boron, aluminum, and oxygen had been used in the fabrication of various devices of optoelectronics [14]. The best crystals for SiC LEDs were doped by nitrogen $\left(10^{18} \ldots 10^{19} \mathrm{~cm}^{-3}\right)$ : $6 \mathrm{H}-\mathrm{SiC}$, 15R-SIC, 33R-SiC. In these crystals, $p-n$ junction had been made by diffusion of aluminum with oxygen (from $\mathrm{SiO}$ powder) or boron with aluminum. Diffusion of $\mathrm{Al}$ with $\mathrm{O}$ was carried out for $2 \mathrm{~h}$ at $1700^{\circ} \mathrm{C}$. Boron and aluminum were diffused for $15 \mathrm{~min}$ at $1600^{\circ} \mathrm{C}$. The sources for oxygen, aluminum, and boron were $\mathrm{SiO}$, $99.99 \% \mathrm{Al}$, and $\mathrm{B}_{2} \mathrm{O}_{3}$, respectively. The optimal depth $(1 \mu \mathrm{m})$ of $p-n$ junctions had been obtained with the crystals heavily doped by nitrogen. But the mechanism of doping had not been yet understood.

The main goal of this article is the better understanding of the diffusion of boron and aluminum in SiC.

\section{Experiment}

Diffusion experiments with boron, aluminum, and oxygen were conducted at temperatures from 1600 to $1700^{\circ} \mathrm{C}$. Very pure original $\mathrm{n}-\mathrm{SiC}$ crystal $(6 \mathrm{H}-\mathrm{SiC})$ specially grown by the Lely method was cut into several pieces. One piece of this crystal was annealed in oxygen during $2 \mathrm{~h}$ at $1700{ }^{\circ} \mathrm{C}$. Another piece was annealed in argon during $2 \mathrm{~h}$ at $1700^{\circ} \mathrm{C}$. The next one was annealed 
with aluminum and silicon oxide powder for $2 \mathrm{~h}$ for aluminum to be diffused. Later on, the same piece was annealed with boron oxide and aluminum for diffusion of boron.

Electrical characteristics of silicon carbide samples was obtained by the Hall effect measurements using the square van der Pauw samples to determine the sheet resistance, mobility, and concentration of free carrier.

According to the equation for space charge neutrality, the electron concentration at equilibrium for two different temperatures is given by:

$$
\begin{aligned}
& \frac{n_{1}\left(n_{1}+N_{a}\right)}{N_{d}-N_{a}-n_{1}}=\beta N_{c}\left(T_{1}\right) e^{\frac{-\Delta E}{k T_{1}}}, \\
& \frac{n_{2}\left(n_{2}+N_{a}\right)}{N_{d}-N_{a}-n_{2}}=\beta N_{c}\left(T_{2}\right) e^{\frac{-\Delta E}{k T_{2}}} .
\end{aligned}
$$

Noncompensated impurities $\left(N_{d}-N_{a}\right)$ can be determined from the extrinsic part of the carrier concentration as a function of temperature. Namely, $\left(N_{d}-N_{a}\right)$ is virtually constant with variation in temperature, until the concentration of intrinsic carriers becomes comparable with that of extrinsic carriers.

The division of Eqs. (1) and (2) gives

$N_{c}(T) \sim A \cdot T^{3 / 2}$.

Then, writing the equation for space charge neutrality for the third temperature $T_{3}$,

$$
\frac{n_{3}\left(n_{3}+N_{a}\right)}{N_{d}-N_{a}-n_{3}}=\beta N_{c}\left(T_{3}\right) e^{\frac{-\Delta E}{k T_{3}}}
$$

we obtain

$$
N_{a}=B_{1} f\left(e^{-\frac{\Delta E}{k T_{1}}}\right), \quad N_{a}=B_{2} f\left(e^{-\frac{\Delta E}{k T_{2}}}\right),
$$

which allows us to determine $\Delta E$.

Very pure single crystal $\mathrm{n}$-SiC specially grown with a concentration of about $10^{17} \ldots 10^{16} \mathrm{~cm}^{-3}$ (at $300 \mathrm{~K}$ ) and $\mu=90 \mathrm{~cm}^{2} / \mathrm{Vs}$ was cut into pieces which were annealed in oxygen for $2 \mathrm{~h}$ at $1700^{\circ} \mathrm{C}$, in argon under the same condition, in oxygen with aluminum (99.9999) during $2 \mathrm{~h}$, and with boron and aluminum in oxygen for $0.5 \mathrm{~h}$.

The temperature dependence of the free carrier concentration is shown in Fig. 1.

Very pure initial (NCO-7) crystal was more compensated and had steeper (a steeper slope) behavior of the plot $\log n=f(1 / T)$ than others (Fig. 1a), the concentration $N_{d}-N_{a}=1.5 \cdot 10^{17} \mathrm{~cm}^{-3}$, and only one donor level at $0.15 \mathrm{eV}$ was working.

After annealing in argon, the concentration of acceptors was decreased, $\left(N_{d}-N_{a}\right)$ was increased, but the plot $\log n=f(1 / T)$ became not so steep (Fig. 1b) and the mobility was increased by two times (Fig. $2 \mathrm{~b}$ as compared with Fig. 2a). This can occur if the impurity distribution became more uniform. The less fold of the dependence $\mu(T)$ at low temperatures gives us an additional evidence for this fact. It can be only if the concentration of $\mathrm{Si}$ vacancies is decreased after annealing in argon. We suggest that Si vacancies have acceptor character.

After annealing in oxygen, $\left(N_{d}-N_{a}\right)$ for the nitrogen level was $2.5 \cdot 10^{17}$ at $0.15 \mathrm{eV}$. But a new deep noncompensated donor level at $0.35 \mathrm{eV}$ appeared (Fig. 1c). This level appears only after annealing in oxygen. The concentration of this level is about $1.06 \cdot 10^{17}$ (nearby the nitrogen concentration at the zero level of compensation).

It can be only if, at first version, oxygen is responsible for this donor level. In the second version, because the crystal surface is covered by the silicon oxide layer, some amount of Si diffuses to the surface creating new Si vacancies. These vacancies bind nitrogen and create complexes which have donor character.

The concentration of noncompensated donors was increased after annealing with aluminum in oxygen (at a level of $0.15 \mathrm{eV}$ it became $4 \cdot 10^{17}$, and $1.5 \cdot 10^{17}$ at $0.35 \mathrm{eV}$ ) as shown in Fig. 1d. It seems unusual since the nitrogen concentration should be decreased when we add acceptor (aluminum).

But, if aluminum occupies $\mathrm{Si}$ vacancies, the concentration of Si vacancies will be decreased due to aluminum, some part of nitrogen will be electrically active again, and, just in this case, we can explain the increase in the free carrier concentration. The plot in Fig. 1d allows us to calculate a new deep level at $0.35 \mathrm{eV}$.

After annealing in the presence of boron, a deeper level appears (but we failed to calculate the level's energy from these data), and the compensation was increased, as usual: see Fig. 1e.

Mobility increases, in common, after annealing, but only annealing in argon leads to the increase in the mobility by two times (Fig. 2a, b). In another cases, the mobility was not so increased because we added additional scattering centers.

\section{Discussion}

A substitution atom of the elements of group III normally acts as an acceptor in SiC since there is a deficit of one valence electron to complete the normal tetrahedral bonding.

A substitution atom of the elements of group $\mathrm{V}$ acts as a donor in SiC. It was discovered that B creates a shallow, as well as a deep, acceptor level.

Nitrogen creates a shallow (six levels depending on the hexagonal-like or cubic-like position) donor's levels. The activation energies of impurities in cubic-like sites are larger than those in hexagonal-like sites.

But can nitrogen create a deep, as well as shallow, donor level? 
A model of deep acceptor level created by boron was suggested in $[15,16]$. The model of $\mathrm{Al}$ and $\mathrm{Ga}$ in deep acceptor states seems to be the "element of group III - vacancy" pair.

Like the case of oxygen in silicon or nitrogen in diamond and in silicon [17, 18], there exists a mechanism for SiC which drives some impurities off the nominal substitutional sites. Acceptor $\mathrm{Al}$ and $\mathrm{Ga}$ atoms occupy the Si-substitutional on-center position and $\mathrm{B}$ and $\mathrm{Be}$ do the off-center position. Nitrogen atoms occupy the C-substitution position.

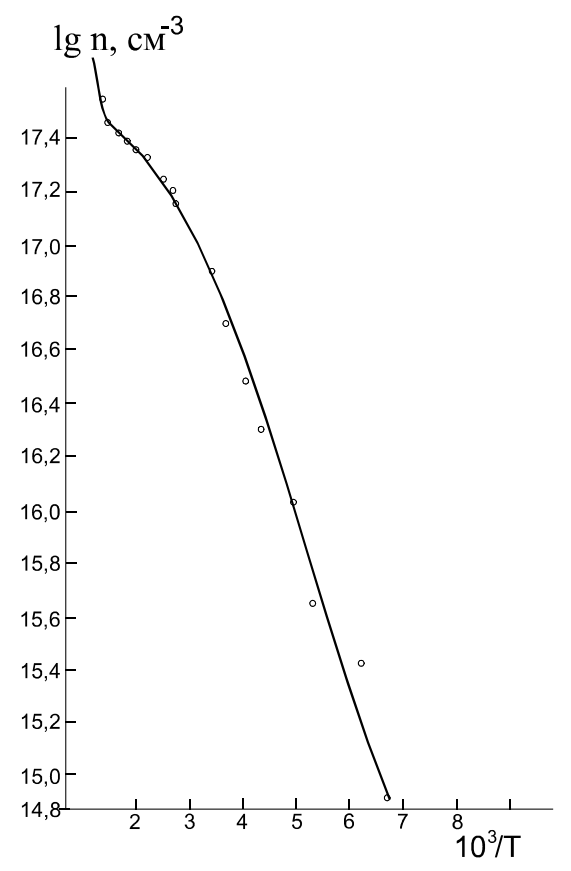

a

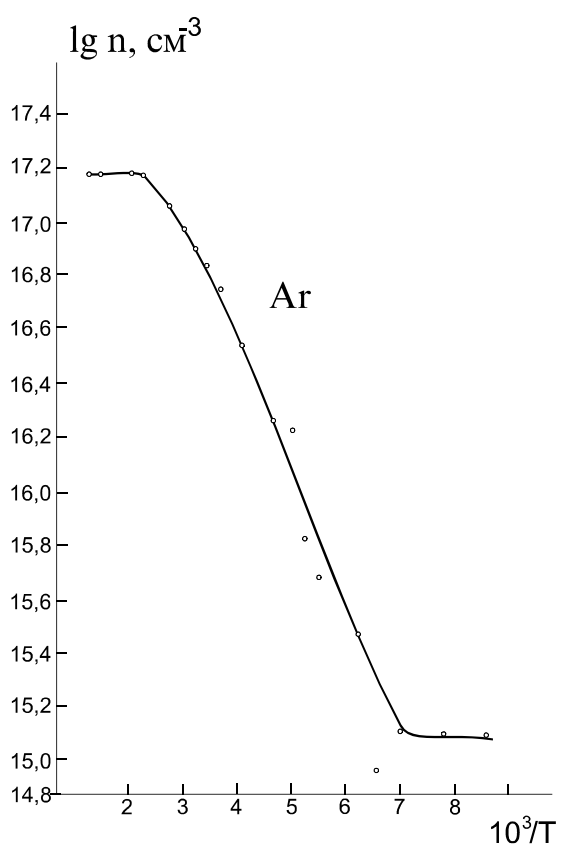

b

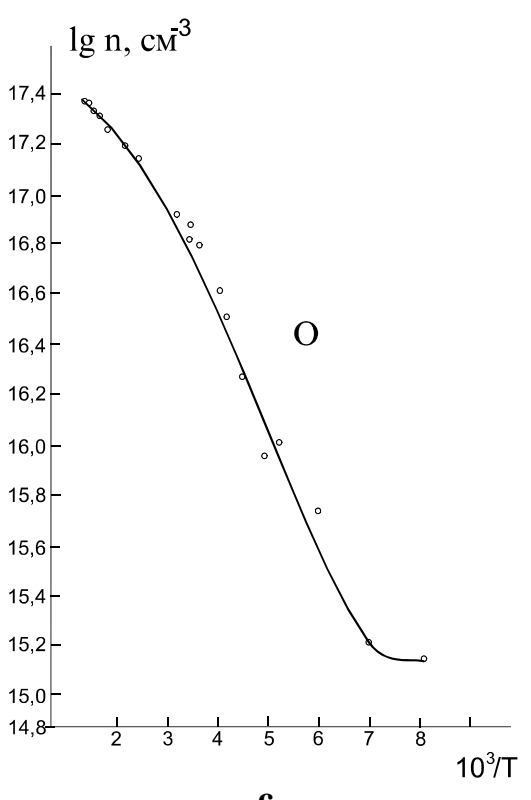

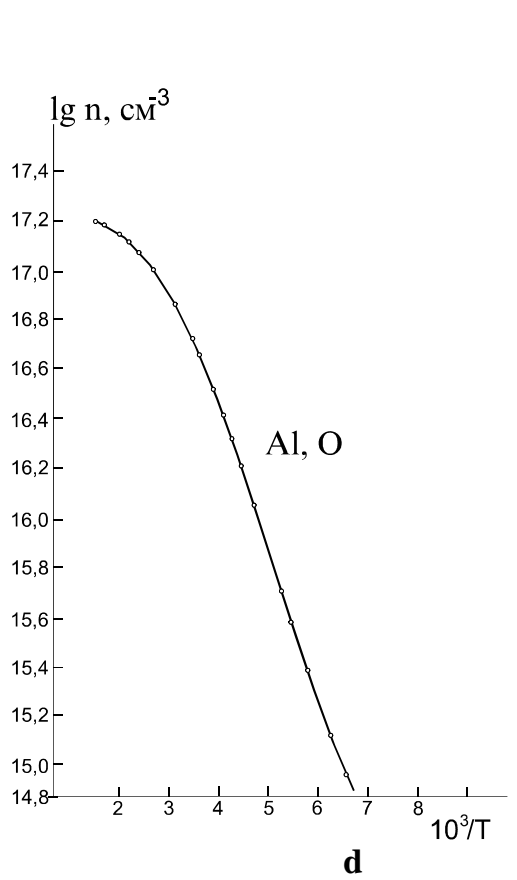

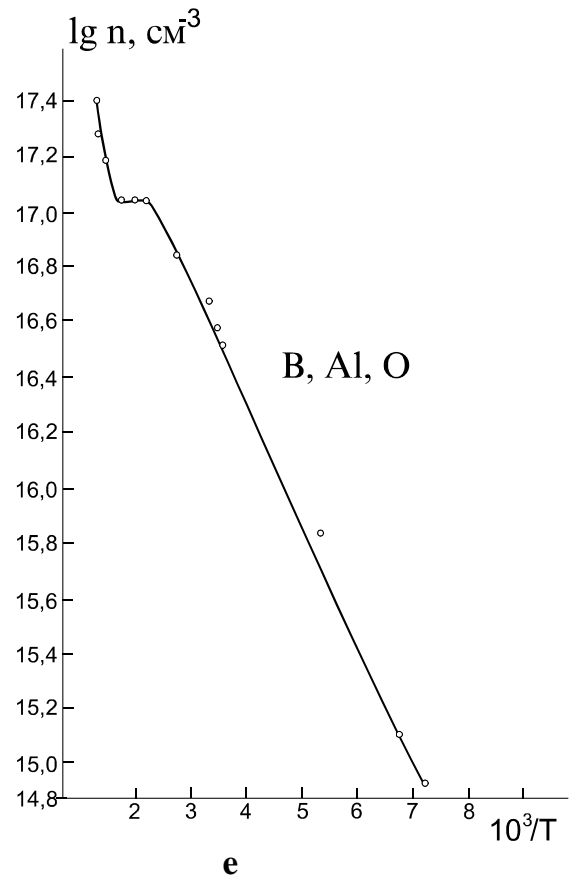

Fig. 1. 

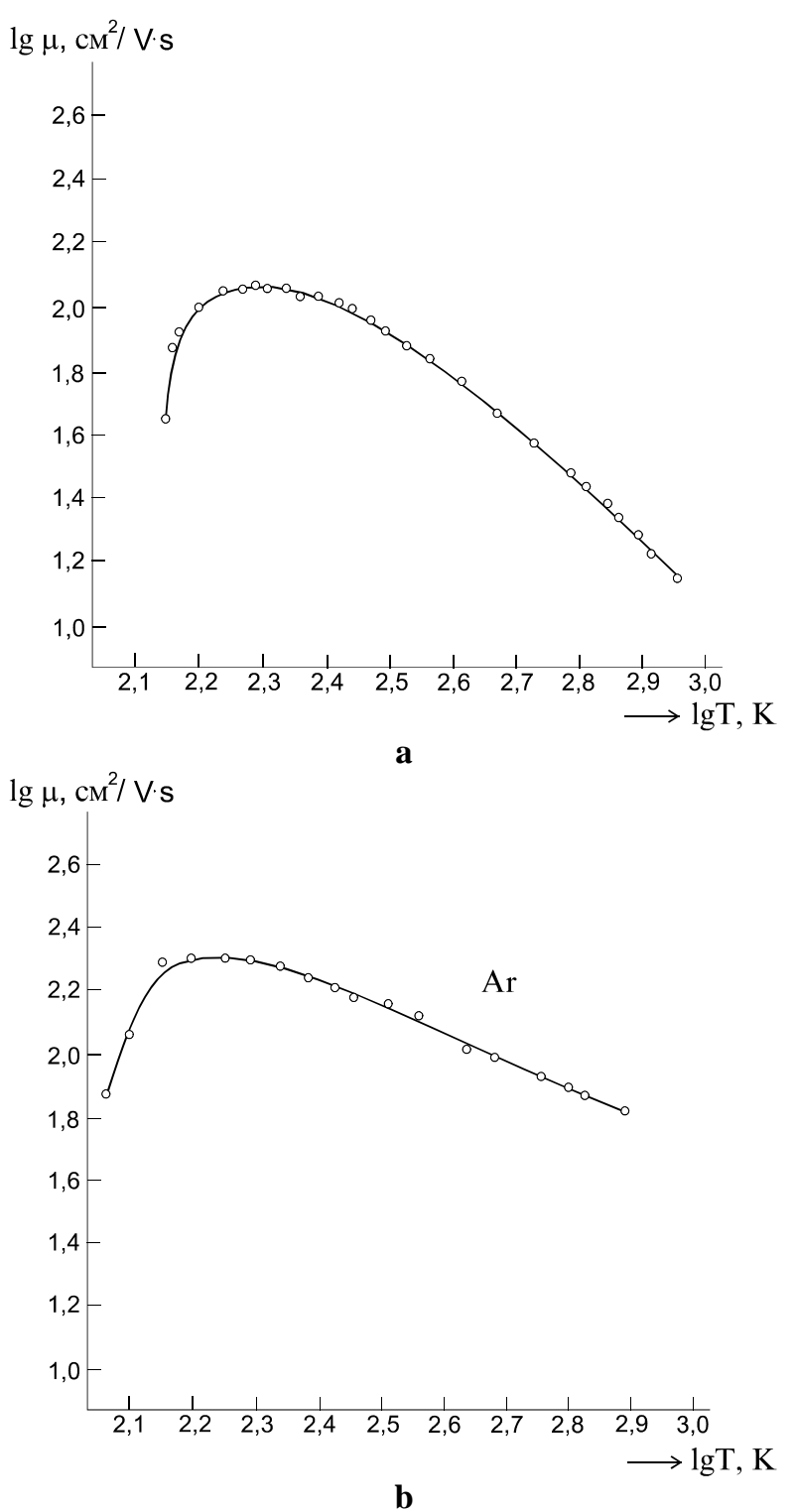

Fig. 2.

We suggest a model of deep donor level created by nitrogen. The model of $\mathrm{N}$ in a deep donor state seems to be the "element of group $\mathrm{V}$ - vacancy" pair as $\mathrm{N}_{\mathrm{C}}$ (like $\mathrm{B}_{\mathrm{Si}}$ ) [16] with the complex which consists of a nitrogen atom replacing a carbon atom (adjacent to a silicon vacancy $\left(\mathrm{V}_{\mathrm{Si}}\right)$ and acts as deep donor $\left(\mathrm{N}_{\mathrm{C}}-\mathrm{V}_{\mathrm{Si}}\right)$ ) similarly to the complex which consists of a boron atom replacing a silicon atom (adjacent to a carbon vacancy $\left(\mathrm{V}_{\mathrm{C}}\right)$ ) and acts as a deep acceptor in the $\left(\mathrm{B}_{\mathrm{Si}}-\mathrm{V}_{\mathrm{C}}\right)$ in model $[15,16]$

In this case, all our experiments can be explained from this point of view.

In particular, bright-yellow luminescence arises due to a deep probably aluminum-related acceptor [21] rather than due to the recombination involving a deep boron center and $\mathrm{N}$ donors or conduction electrons $[19,20]$. We suggest that the characteristic hightemperature bright-yellow luminescence in annealed $6 \mathrm{H}$ $\mathrm{SiC}$ [22], 4H-SiC [23], and heavy doped 6H-SiC [13] is due to the recombination involving a deep nitrogen center as the complex consisting of a nitrogen atom replacing carbon with adjacent silicon vacancies $\left(\mathrm{V}_{\mathrm{Si}}\right)$ and acting as a deep donor as well. In annealed crystals, deep donors and deep acceptors exist together. The chemical nature and structure of D- and Z-centers, and the acceptor or donor character of deep levels [22, 24] are else open questions.

We mention also another possible model, in which nitrogen replacing $\mathrm{Si}$ with adjacent carbon vacancies $\left(\mathrm{V}_{\mathrm{C}}\right.$ ) (if B can occupy a C-site, why cannot N occupy a Si-site?) creates a deep donor level. For example, a nitrogen atom responsible for $0.35 \mathrm{eV}$ replaces carbon with adjacent silicon vacancies $\left(\mathrm{V}_{\mathrm{Si}}\right)$ responsible for $0.74 \mathrm{eV}$ or vice versa. But this looks not so reasonable. A nitrogen atom replacing carbon with adjacent silicon vacancies $\left(\mathrm{V}_{\mathrm{Si}}\right)$ and acting as a deep donor seems more suitable.

\section{Conclusion}

So, we can see that all these data of the experiments with very pure $\mathrm{SiC}$ crystals $\left(10^{17} \ldots 10^{16} \mathrm{~cm}^{-3}\right)$ can be explained only on one base by the participation of vacancies in the diffusion process. A nitrogen atom replacing a carbon atom creates the "element of group $\mathrm{V}$ - vacancy” pair ( $\mathrm{N}_{\mathrm{C}}$ with adjacent silicon vacancies $\left.\mathrm{V}_{\mathrm{Si}}\right)$ and acts as a deep donor $\left(\mathrm{N}_{\mathrm{C}}-\mathrm{V}_{\mathrm{Si}}\right)$ similarly to the complex consisting of a boron atom replacing a silicon atom with adjacent carbon vacancies $\left(\mathrm{V}_{\mathrm{C}}\right)$.

\section{References}

1. http://www.grc.nasa.gov/www/SiC (internet information).

2. S.C. Kim, W. Bahng, N.K. Kim, E.D. Kim, T. Ayalew, T. Grasser and S. Selberherr // Materials Science Forum 483-485, p. 793-796 (2005).

3. S.I. Vlaskina, Silicon carbide LED // Semiconductor Physics, Quantum Electronics \& Optoelectronics, 5(1), p. 71-75 (2002).

4. Simulation, devices, and process technology in silicon carbide, research project of the department of microelectronics and information technology, http://www.imit.kth.se//forskningsprojektdetalj.html?projektid=2

5. Dallas Morisette, Mitch McGlothlin, J.A. Cooper, Jr., M.R. Meloch, SiC Shottky barrier diodes development at Purdue // http:/www.enc.purdue.edu/ WBG/Device-research/Shottky-Diodes/index.html

6. Diffusion in bulk crystals and heterostructures of compound semiconductors. http://www.unimuenster.de/Rectorat/Forschungsberichte2000/foll gd03.htm

7. H. Bracht, N.A. Stolwijk, M. Laube, G. Pensl, Diffusion of boron in silicon carbide: Evidence for the kick-out mechanism // Appl. Phys. Lett. 77, p. 3188-3190 (2000). 
8. H. Bracht, N.A. Stolwijk, M. Laube, G. Pensl, Modelling of boron diffusion in silicon carbide // Mater. Sci. Forum 353-356, p. 327-333 (2001).

9. Doping issues in wide band-gap semiconductors, Exeter, United Kingdom, 21-23 March, 2001. http://widegap2001.ex.ac.uk/sic.html.

10. M. Bockstedte, A. Mattausch, and O. Pankratov, Boron diffusion in SiC: the role of intrinsic point defects. k2000/abstracts/MichelBockstedte.html.

11. Peter Deak, Materials characterization and modeling of SiC in Europe - From the viewpoint of a theorist // Mater. Sci. Forum 483-485, p. 457-464 (2005).

12. Birnie, P. Dunbar, A model for silicon self diffusion in silicon carbide: anti-cite defect motion // J. Amer. Ceram. Soc. 69, p. $33-35$ (1986) (http://www.mse.arizona.edu/faculty/birnie/abs860 1.html).

13. S.I. Vlaskina, D.H. Shin, Effect of annealing on the impurities of 6H-SiC single crystals // Jpn J. Appl. Phys. Part 2 -Letters, 38, p. L861-L863 (1999).

14. S.L. Vlaskina, K.W. Kim, Y.S. Kim, Y.P. Lee, G.S. Svechnikov, Optoelectronics devices on silicon carbide // J. Korean Phys. Soc. 30 (910), p. 117-121 (1997).
15. P.G. Baranov, I.V. Ilyn and E.N. Mokhov // Solid State Communs 100, p. 371 (1996).

16. A.V. Duijn-Arnold, T. Ikoma, O.G. Poluektov, P.G. Baranov, E.N. Mokhov and J. Schmidt // Phys. Rev. B 57(3), p. 1607 (1998).

17. G. Bachelet, G.A. Baraff and M. Schulter // Phys. Rev. B 22, p. 2842 (1980).

18. S.T. Pantelides, W.A. Harrison and F. Indurain // Phys. Rev. B 34, p. 6038 (1986).

19. H. Kuwabara and S. Yamada // Phys. status solidi (a) 30, p. 739 (1975).

20. M. Ikeda, H. Matsunami and T. Tanaka // Phys. Rev. B 22, p. 2842 (1980).

21. E.N. Kalabuhova, S.N. Lukin, E.N. Mokhov, J. Reinke, S. Greulich-Weber and J.M. Spaeth // Inst. Phys. Conf. Ser. 142, p. 333-335 (1996).

22. W. Suttrop, G. Pensl and P. Lanig // Appl. Phys. A 51, p. 231-237 (1990).

23. T. Troffer, Ch. Habler, G. Pensl, K. Holzlein, H. Mitlhner, J. Volki // Inst. Phys. Conf. Ser. 142, p. 281-284 (1996).

24. P.G. Baranov and E.N. Mokhov // Inst. Phys. Conf. Ser. 142, p. 293-296 (1996). 